\title{
An Architectural-model for Context aware Adaptive Delivery of Learning Material
}

\author{
Kalla. Madhu Sudhana \\ Ph.D. Scholar, Dept. of C. S. E, \\ St. Peter's University, \\ Chennai, India.
}

\author{
V. Cyril Raj \\ Head, Dept. of Computer Science, \\ Dr. M.G.R University, \\ Chennai, India
}

\author{
T.Ravi \\ Principal, \\ Srinivasa Institute of Engg \& Tech, \\ Chennai, India
}

\begin{abstract}
The web based learning has become more complex to search required learning resources with continuously growing digital learning contents which are entangled with structural and semantic interrelationship. Meanwhile, the rapid development of communication technology lead to heterogeneity of learning devices than it was in the early stage. The context-aware adaptive learning environment has become a promising solution to these searching and presentation problems in educational domain. To solve this context aware learning content delivery problem, we proposed a novel architectural model based on MVC (ModelView-Controller) design pattern, that is able to perform personalized adaptive delivery of course content according to learner contextual information such as learning style and characteristics of the learning device using an ontological approach.
\end{abstract}

Keywords-MVC design pattern; context-aware adaptive learning; architectural model; Usability Analysis

\section{INTRODUCTION}

In an adaptive e-learning environment, the system must respond harmoniously to changes of learner needs, learning style and context. The e-learning approach such as online learning is empowering the students for self-learning and to create personalized context aware adaptive learning approaches, through leveraging the huge digital learning resources that are available on internet.

The recent emerging mobile communication technology and the popularity of mobile solutions have geared the traditional PC based e-learning approach to increase their change to m-learning, but the divergence between these two types of environments based on their technical capabilities and characteristics has become a paradox to use existing digital learning contents and applications that are developed with the perspective of computers.

Therefore, various content adaptation (transcoding) techniques emerged to perform the adaptation of learning contents based on the characteristics of learning devices. These single-source adaptation techniques often lead to high complexity and cumbersome task to deliver the adapted contents dynamically as per the characteristics of client device, this need to develop multi-source authoring contents, where separate resources are maintained for each class of devices. In the proposed prototype implementation we are considering only two types of resources as compatible for PC and mobile environments.
Here, we proposed an architectural framework for context aware adaptive content delivery for course based e-learning environments. The novel feature of our architectural approach uses the recent MVC (Model-View-Controller [1]) architectural design pattern that provides the benefits such as: code reusability, upgradability and multiple views of the same data. Another important feature is ontology-based learner context model that helps in accessing the concepts that are contextually and conceptually suitable for learner needs.

\section{RELATED RESEARCH WORK}

Jane Yau [2] proposed context-aware and adaptive learning architecture, through dividing the dimensions of adaptation into two separate layers as: learning styles and knowledge level as learning preferences in adaptation layer and location and time as contextual features of adaptation layer. Yau [3] introduced the Context-aware and Adaptive Learning Schedule (CALS) framework, in which they considered learning activities, learner profile and learner schedule events as context dimensions. Through considering learner's personal features, preferences and previous actions as contextual profile, Martin [4] presented an architecture of a system, based on modularization of the adaptation layer that supports contextbased adaptation for m-learning. Agile e-learning system architecture proposed by Finke [5] with the features such as adaptability, reusability and changeability provides an opportunity for dynamic curriculum exposition.

The personalized multi-agent e-learning system architecture proposed by Baylari [6] uses an item response theory and artificial neural network to recommend appropriate learning materials to the learner through diagnosing learner's learning activity. As quoted by He, Daqing [7], ontology can provide the visual presentation of conceptual structure about the course topics and Dicheva [8] stated that the conceptual structure of the course content helps in getting the orientation of learning task.

\section{OBJeCtives OF PRoposed APPROACH}

The main objective of proposed system is to improve learner's knowledge and to facilitate the learner to review course contents at any moment of time. The development of new generation of e-learning applications has to leverage the technical advancements in digital learning devices to obtain potential benefits. Here, we noticed two important technical strategies that are to be considered while developing the new 
generation of e-learning applications. The two strategies and

their concerned targets and benefits are as shown in "Table I".

TABLE I. OBJECTIVES OF PROPOSED APPROACH

\begin{tabular}{|c|c|c|}
\hline Strategies & Target & Benefits \\
\hline \multirow{3}{*}{$\begin{array}{l}\text { Ontology based content } \\
\text { organization and } \\
\text { presentation of course } \\
\text { material }\end{array}$} & \multirow{3}{*}{$\begin{array}{l}\text { Increasing learners } \\
\text { understanding capability, } \\
\text { critical thinking and problem } \\
\text { solving skills. }\end{array}$} & $\begin{array}{l}\text { Providing foundation material, such as prior and related materials of } \\
\text { current learning concept. }\end{array}$ \\
\hline & & Extends learning beyond the stipulated course contents. \\
\hline & & $\begin{array}{l}\text { Learner can navigate and read all other concepts which are } \\
\text { conceptually related to course contents. }\end{array}$ \\
\hline \multirow{3}{*}{$\begin{array}{l}\text { Device independent } \\
\text { adaptive delivery of } \\
\text { learning resources }\end{array}$} & \multirow{3}{*}{$\begin{array}{l}\text { Increasing student } \\
\text { engagement towards learning } \\
\text { course. }\end{array}$} & $\begin{array}{l}\text { Learner can read class material that is not offered or covered in regular } \\
\text { classes. }\end{array}$ \\
\hline & & Learner is able to review materials as many times as needed. \\
\hline & & $\begin{array}{l}\text { Mobile-learning helps learner, to review course material at any moment } \\
\text { of time and place, when ever and where ever they want, so it will } \\
\text { improve student engagement in learning. }\end{array}$ \\
\hline
\end{tabular}

\section{A. Ontology based content organization and presentation}

An ontological approach provides the management and organization of course material based on their semantic inter relationships. In order to improve the understanding ability of learner, this can help e-learning application developers to search and present related knowledge of particular learning topic.

It is ambivalent to make the learner ambulate among learning concepts with one perspective. It is willingness of learner to navigate based on his cognitive skills and learning style. As proposed by Brusilovsky [9] the pool of course concepts are connected to form heterarchy (Where items are likely to be related in two or more differing ways) as shown in "Fig. 1".

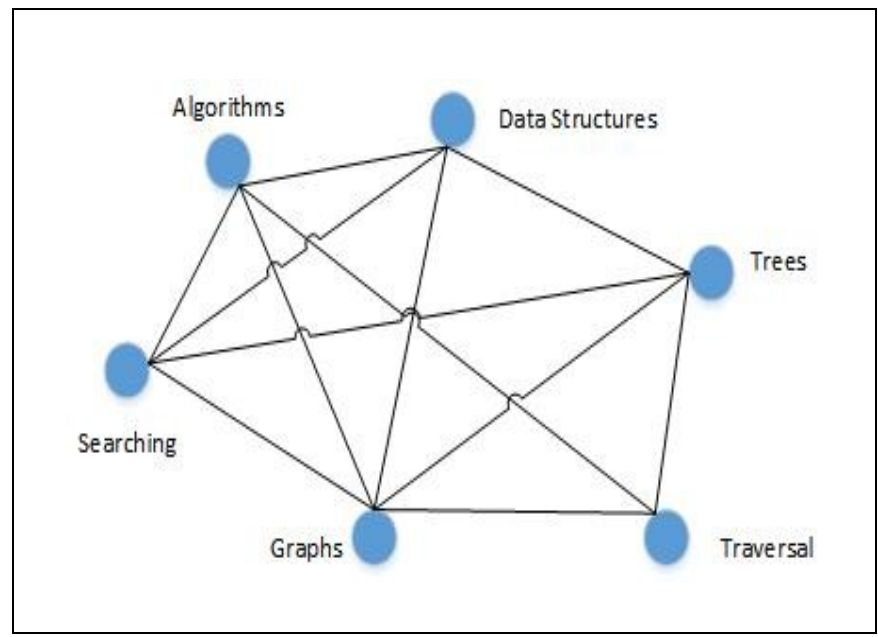

Fig. 1. Interrelation among pool of concepts

Learner may have different viewpoints, cognitive skills and knowledge levels of learning materials [7] and as mentioned by Dicheva [8] the students are often unaware of the context of the learning task when they start to learn new concepts.
The proposed presentation approach makes the learner to learn and interpret the correlated and in-depth concepts of learning domain so that, the learner get exposed to higher order thinking skills and makes him professional in the discipline.

Course structure ontology: The ontology based knowledge modeling and presentation of course contents, facilitates the learner to understand everything related to particular learning concept. The graphical representation of various topics of proposed course ontology can be formally represented as $\mathrm{G}$ ( T, $\mathrm{P}, \mathrm{R})$, where $\mathrm{T}=$ Set of topics of specific course or subject; $\mathrm{P}=$ is the property set such as ID, Name, Description, etc.; $\mathrm{R}=$ is the relation set indicating the semantic relationships between the pair of topics as shown in "Fig. 2".

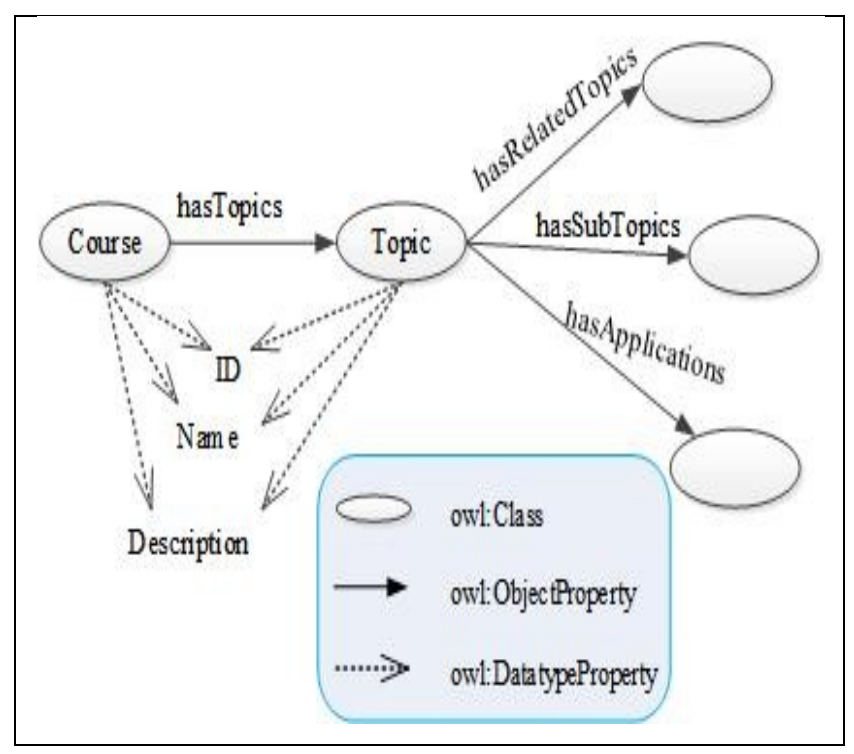

Fig. 2. Partial course structure ontology

For example consider the subject "Data Structures", it can act as "Course class", some of the "Topic classes" and their conceptual relations with various subtopics are as shown in "Table II". 
TABLE II. ONTOLOGICAL DESCRIPTION OF "DATA STRUCTURES" SUBJECT

\begin{tabular}{|l|l|l|l|}
\hline $\begin{array}{l}\text { Topics } \\
\text { (Topic classes) }\end{array}$ & $\begin{array}{l}\text { Related Topics } \\
\text { (hasRelatedTopics) }\end{array}$ & $\begin{array}{l}\text { Sub Topics } \\
\text { (hasSubTopics) }\end{array}$ & $\begin{array}{l}\text { Applications } \\
\text { (hasApplications) }\end{array}$ \\
\hline Trees & $\begin{array}{l}\text { Graphs, Traversal, } \\
\text { Algorithms }\end{array}$ & Binary trees, AVL Trees, Traversal & Heap Sort, Directory Structure \\
\hline Stacks & Queues, List, Arrays & PUSH, POP & Recursion, Buffer Storage, DFS \\
\hline Queues & List, Arrays & D-Queue, P-Queue & Multi-tasking, BFS \\
\hline Graphs & Trees, Network, Maps & Traversal, BFS, DFS & $\begin{array}{l}\text { Multi Processor Scheduling, PERT- } \\
\text { Network }\end{array}$ \\
\hline
\end{tabular}

\section{B. Device independent e-learning}

Through customized device independent course based elearning applications the students can review their class materials and can refer extra help in topics that are hard to them. Morar [10] proposed that, converging of the computer based e-learning and mobile based m-learning allows students to stay connected with the learning environment and learning resources no matter where they are.

The communication technology geared the traditional computer based e-learning to increase their change to $\mathrm{m}$ learning. With the release of Wireless Application Protocol (WAP) version 2.0, the wireless world got closer to the internet access and with that, the mobile technology (such as smart phones) has influenced the students to embark in to mobile based accessing of learning material.

The mobile usage statistics (comparing 2006 and 2011) released by "Speak Up 2012 National Report" survey [11] shown in "Fig. 3" stating that, the Smartphone and Tablet PC usage is increasing exponentially.

The students' mobile usage (which have internet access capability) growth initiated the traditional PC based e-learning applications to consider mobile context while developing and delivering learning resources.

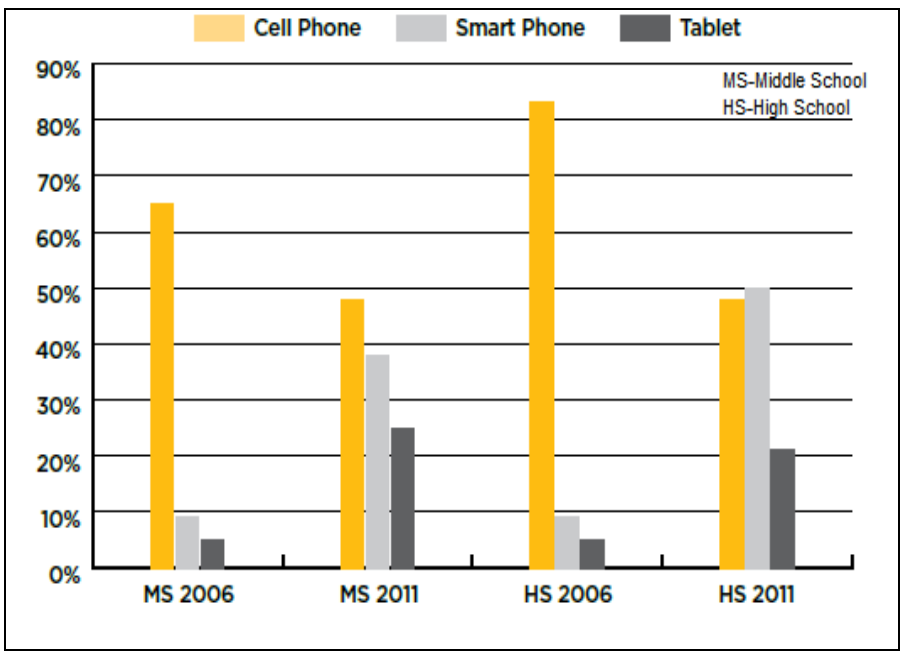

Fig. 3. The change in students' mobile usage [11]

\section{PROPOSED ADAPTATION APPROACH}

This section describes the content adaptation framework for context aware web-based learning environment.
Different features of proposed adaptation approach are as shown in "Table III", based on which the concerned architectural model is designed and implemented.

TABLE III. FRAMEWORK OF PROPOSED ADAPTATION SYSTEM

\begin{tabular}{|l|l|}
\hline Feature & Approach \\
\hline $\begin{array}{l}\text { 1. Locality of adaptation } \\
\text { mechanism }\end{array}$ & Server side approach \\
\hline $\begin{array}{l}\text { 2. Content of the context } \\
\text { adaptation }\end{array}$ & $\begin{array}{l}\text { Device centric and User centric (Device } \\
\text { profile and Learner preferences) }\end{array}$ \\
\hline 3. Learner context space & $\begin{array}{l}\text { Run-time perspective (Explicit context } \\
\text { model) }\end{array}$ \\
\hline $\begin{array}{l}\text { 4. Usage environment of } \\
\text { proposed system }\end{array}$ & For course based e-learning \\
\hline $\begin{array}{l}\text { 5. Approach of adaptation } \\
\text { mechanism }\end{array}$ & An ontology based semantic approach \\
\hline 6. The server of content & $\begin{array}{l}\text { Content versioning and ontology based } \\
\text { identification }\end{array}$ \\
\hline
\end{tabular}

\section{A. Locality of adaptation mechanism}

Domain and learner models are connected with the help of adaptive model [12]. The adaptive model may be in server, client or in proxy. In the proposed system, the adaptation model is in server side as shown in "Fig. 4". In the server side adaptation approach the server is responsible for identifying the suitable content based on the client device capabilities. The main advantage of using server-side adaptation is: the server usually has much more processing power than the client devices, so that server can dynamically perform adaptation according to learner device capabilities.

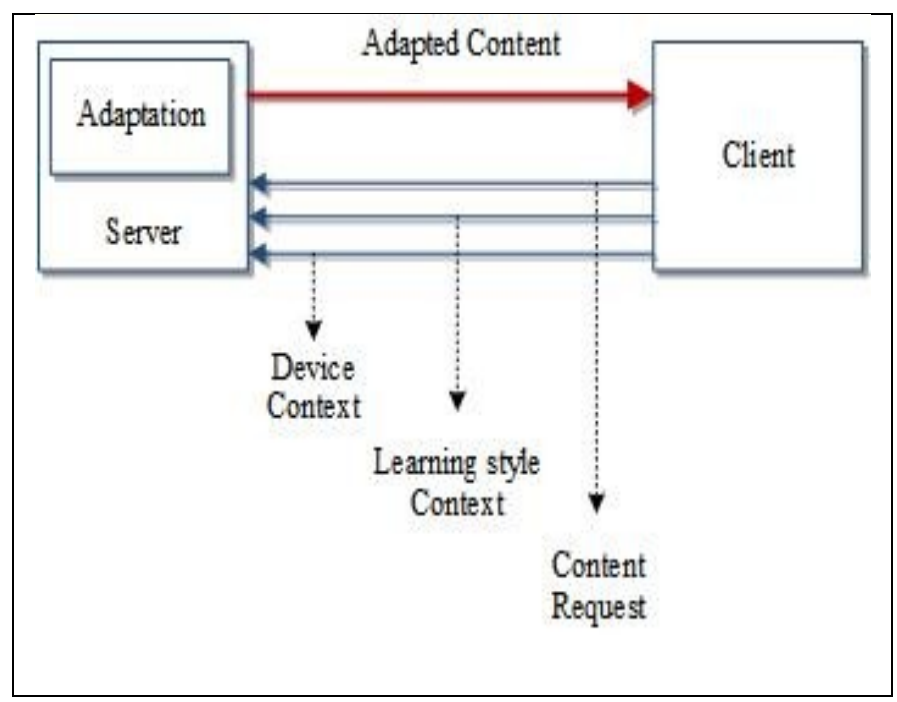

Fig. 4. Locality of adaptation mechanism 


\section{B. The content of the context adaptation}

Device-centric and User-centric are the two content adaption approaches that we can consider based on what context the content is being adapted. In the proposed system, from the device centric perspective we consider the type of device (PC or Mobile) and their software and hardware details obtained through User Agent of HTTP request and from the user (learner) perspective we deal with Resource Type and Learning style of e-learner, obtained from user interface by activity monitoring system.

\section{Learner context space}

Based on learner context space, the adaptation approach can be considered as: development-time perspective (adaptation logic is directly hard coded in application) and run-time perspective (through explicit context model, based on which the adaptation behavior changes dynamically). The proposed system is designed with an explicit adaptation mechanism which dynamically decides the device type and learning context of learner.

\section{Usability of system}

The system is designed for the purpose of context aware adaptive delivery of learning resources. It is mainly developed for course based e-learning environment where the course contents are being organized and managed with adaptation oriented resource description ontology so as to deliver the contents based on device capabilities and learner preferences.

\section{E. Adaptation mechanism}

The adaptation mechanism in the system is based on device context and learning style of e-learner. The proposed system is not an adapted system, but it is the combination of adaptive system (automatic finding of device context) and adaptable system (learner needs to enter learning style context).

1) Device context: The proposed system is able to dynamically update the device profile through analyzing the "User Agent Profile [13]" received from HTTP request.

2) Learner context: The users need to specify their preferences explicitly, during registration process, which can be modified during the process of learning by the user's intervention.

As shown in "Fig. 5" the adaptive decision making is based on set of rules (facts) that specify how the system acts. The system examines the condition under "IF" statement in the set of all rules, if the condition of any rule is satisfied then the operation under the "THEN" statement is performed. The general form of rule statement is: If <premise $>$ then $<$ consequent $>$.

\section{$F$. The server of content}

The content server maintains separate versions of resources for mobile and PC clients.
The learning contents are authored for two different categories of clients. The suitable content is identified using resource description ontological metadata as per the context of learner.

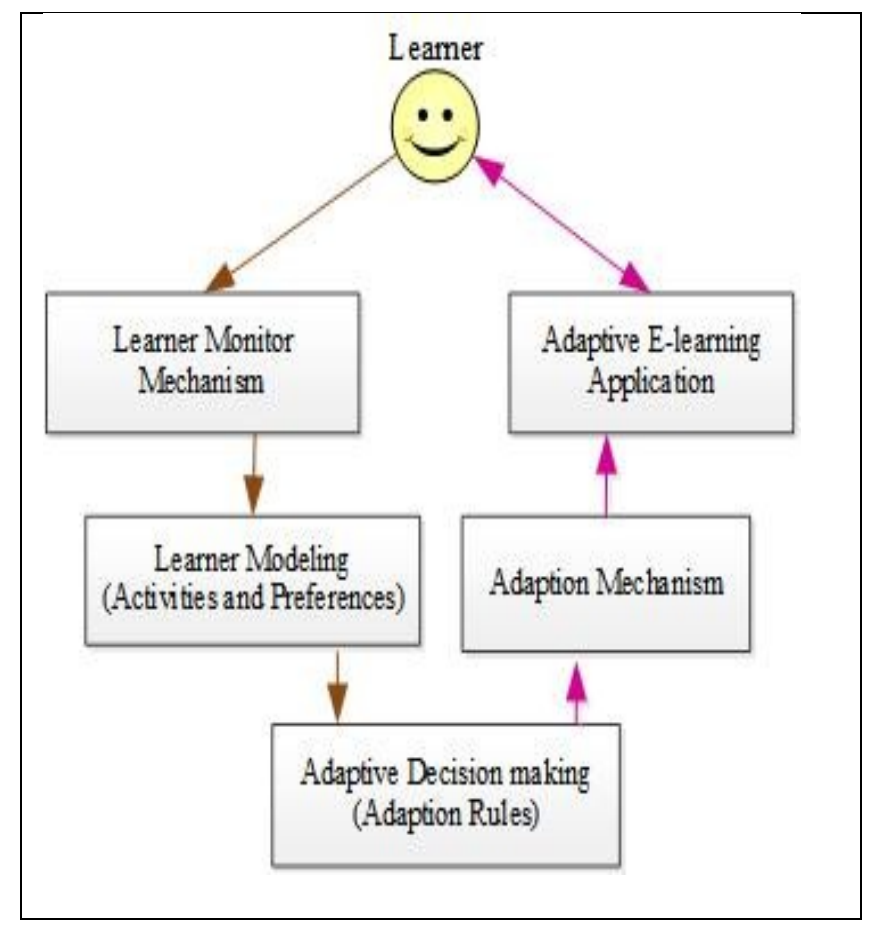

Fig. 5. Components of adaptation mechanism

\section{Design Pattern of Proposed Architecture}

MVC (Model-View-Controller) architectural design pattern is one of the recent developments in Microsoft ASP.NET technologies. As we are aiming to develop web based e-learning system, this approach isolates the application logic from the users input and presentation (User Interface) environment, so that using this model in the architecture of proposed context aware adaptive e-learning system, it can offer dynamic content adaptation to provide various presentation formats for various client devices.

According to MVC system, the main components are M (Model), V (View) and C (Controller) which can be defined as:

1) Controller: It handles the user interaction and input logic received from View and based on Model.

2) Model: Handles the business logic (rules) and data. It is independent of other parts of Controller and View.

3) View: Is an output representation of Model data and View knows about only Model.

The generic MVC design pattern [14] has been modified so as to make it suitable for context aware adaptive e-learning system, as shown in "Fig. 6". 


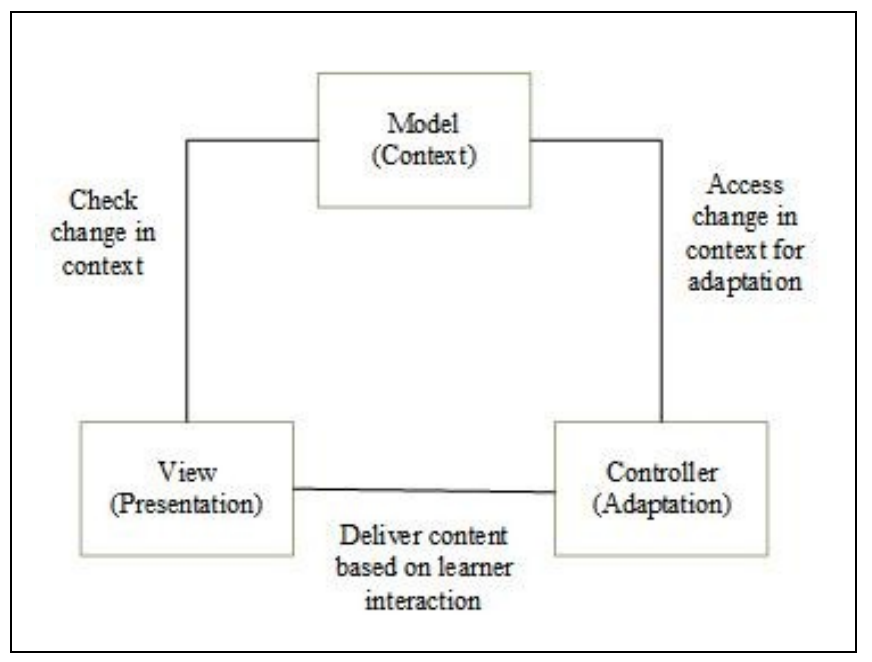

Fig. 6. MVC based design pattern for context aware adaptive e-learning system.

\section{ARChitecture of Proposed SyStem}

The architecture of proposed context aware adaptive system is developed based on the MVC design pattern as we discussed in the previous section; the three different components and their relation is as shown in "Fig. 7".

The functionality of these components in the proposed context aware adaptive e-learning system architecture is:

1) Controller: (Context detection and adaptive mechanism) the controller is responsible to notice, from what type of learning device it has received the request and then redirects to suitable view (web page). The events that are occurring through learner interaction should be captured by the controller and trigger the concerned events to change the model.

2) Model: (Information storage and query processing) it describes learner context, adaptation logic and learning content repositories. Based on adaptation logic it feeds suitable data to the view and it responds based on context information received from controller and notifies the view to update the display.

3) View: (User Interface) it is an output representation of model data and is considered as dumb. In the proposed system, it is a web browser with internet connection. View knows only about model, so it can present data based on model.

In the context of proposed context aware adaptive elearning system architecture, the client device sends HTTP request to Web Server (e.g. IIS). The context detection mechanism (Controller) implemented in web server receives the request and identifies the device type based on the User Agent Profile headers. The device context gets stored along with learner preferences under concerned learner context-id as learner context information (Model).

When the learner access for learning contents, the Controller's Action class passes request to adaptation logic that is responsible for delivering suitable content from concerned database and as per the presentation logic (View) that is based on the device context and learning style of e-learner.

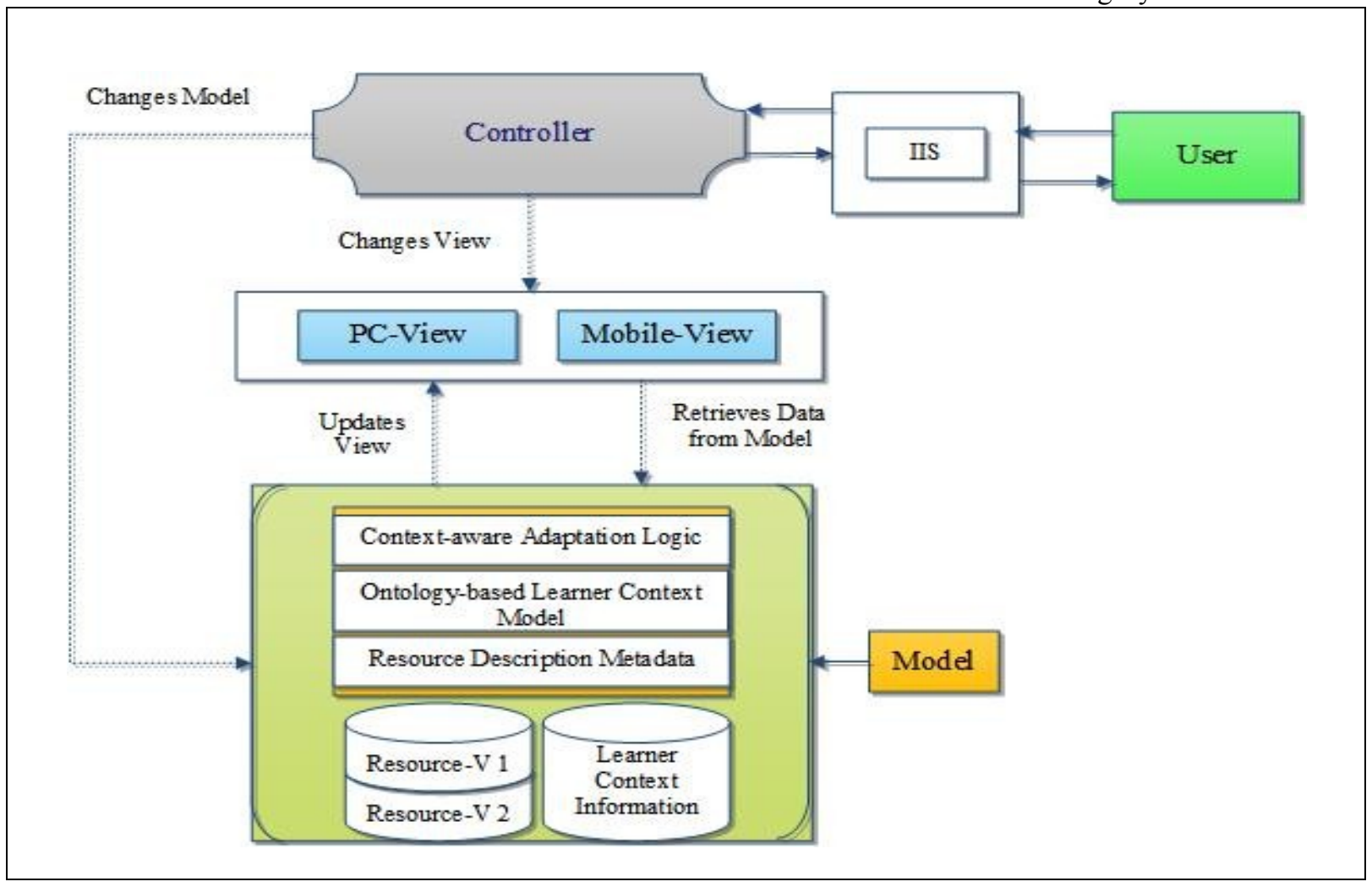

Fig. 7. MVC Pattern based system architecture 


\section{SYSTEM DESCRIPTION}

To evaluate the proposed MVC oriented architecture model for context aware adaptive delivery of learning resources, we preferred to develop course based e-learning prototype application. This web-based prototype is implemented to deliver the contents based on contextual information such as device properties and learner preferences.

The desired goal of proposed system is not just a function of how the course material is organized and delivered, but to influence and initiate learner's learning process so as to acquire new knowledge through presenting conceptually related information of current learning concept. The delivery of content is based on learner context to reduce the precision of search results.

\section{A. Test bed scenario}

The proposed system is designed and developed in such a way to recognize whether the accessing device is Mobile or PC and then it redirects the learner to the suitable web pages. The redirection of learner to device specific URL is based on the User-agent in the HTTP request headers. An example of "HTTP header" and "User Agent" formats is as shown in "Table IV".

In the proposed system an optimized web pages is designed based on the presentation capabilities of feature-phones and smart-phones and the test bed scenario is as shown in "Fig. 8".
TABLE IV. EXAMPLE OF “HTTP-HEADER" AND "USER-AGENT"

An example HTTP header of PC-Client looks like this:

Connection=keep-alive

Accept-Encoding=gzip

Accept-Language $=$ en-US

Host $=\mathrm{http}: / /$ localhost/Default.aspx

User-Agent= Mozilla/5.0 (Windows NT 6.1; rv: 22.0) Gecko/20100101

Firefox/22.0

An example of User Agent of PC 2003 SE Emulator:

Mozilla/4.0 (Compatible; MSIE 4.01; Windows CE; PPC; 240 x 320)

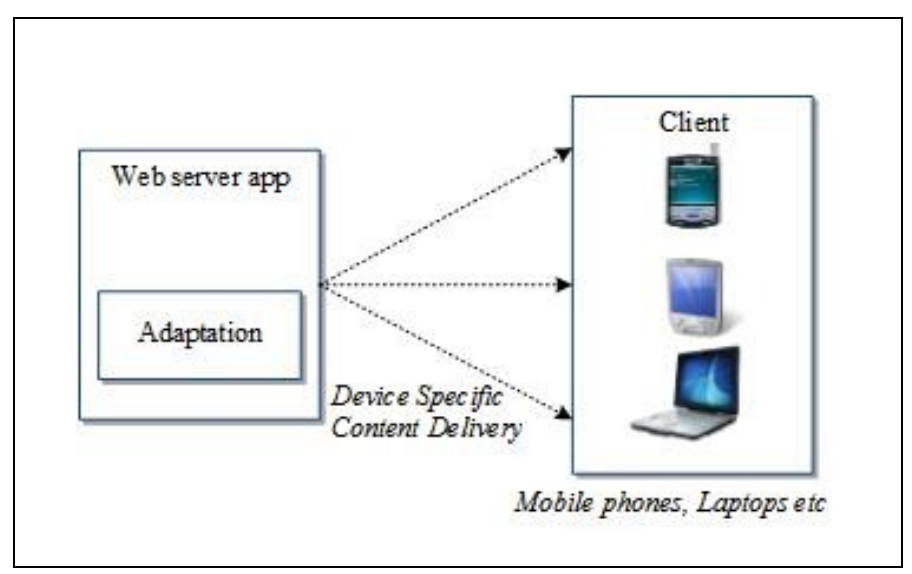

Fig. 8. Test bed scenario of context aware delivery

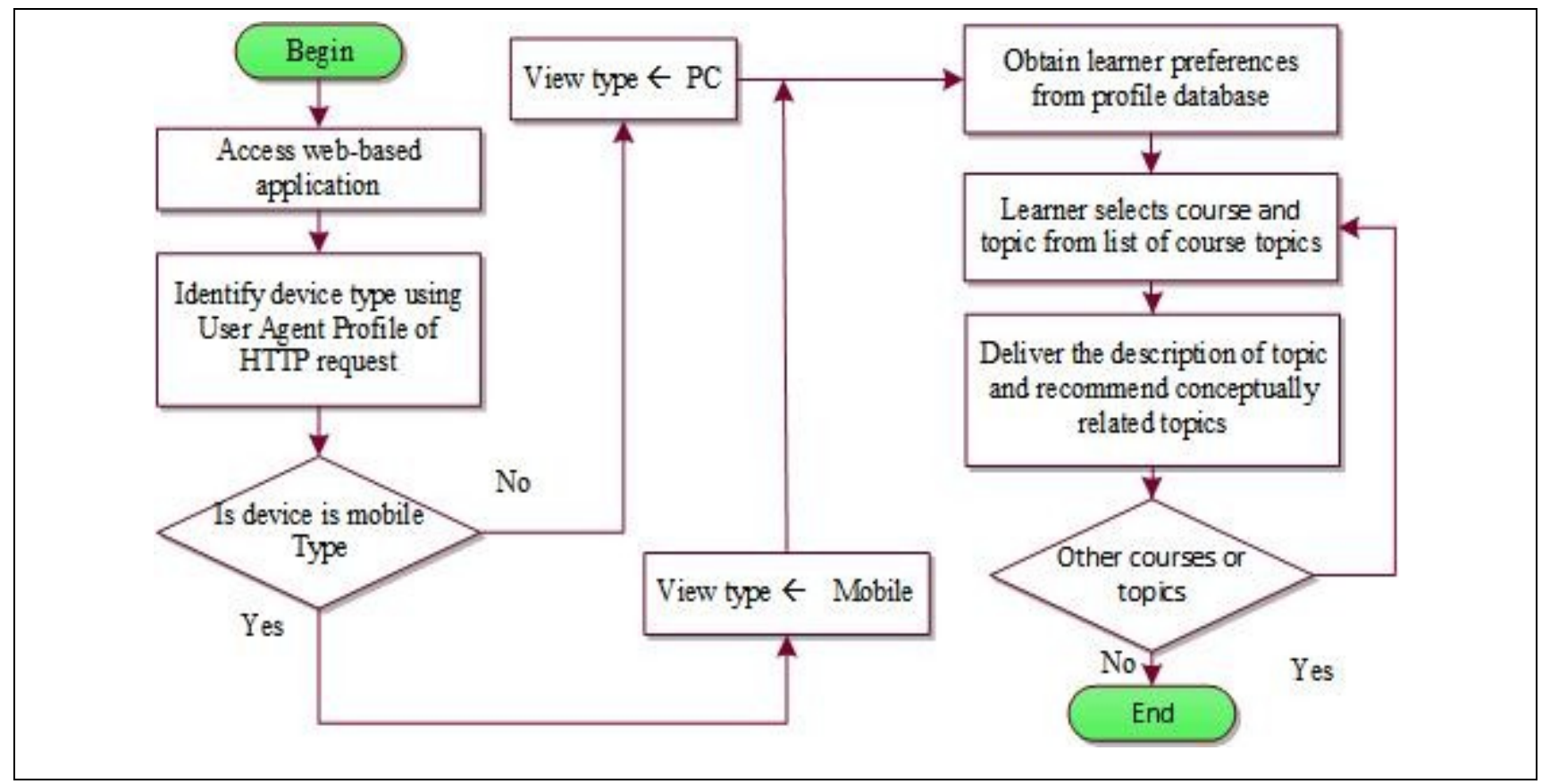

Fig. 9. The flowchart of system working process

\section{B. Working process of system}

1) Pre requisites: student needs to undergo the registration process through form filling approach that collects personal details of learner and allocates user-id and password for authentication purpose. The learner has flexibility to use any type of learning device such as mobile or $P C$ as the system is designed to detect device context automatically.

2) Device detection: System detects the device type using User Agent Profile of HTTP request received from client machine and it is considered as device context. 
3) Acquiring learner style: the learner needs to enter the preferences and learning style before starting to learn particular course.

4) Course selection and navigation: learner needs to select his preferred course of learning from list of courses, then the system provides concepts of concerned course and learner can navigate through concepts, sub concepts and so on.

5) Content delivery: The system retrieves the content from content repository along with details such as related concepts, examples etc, based on resource description ontology.

The flowchart of system working process is as shown in "Fig. 9".

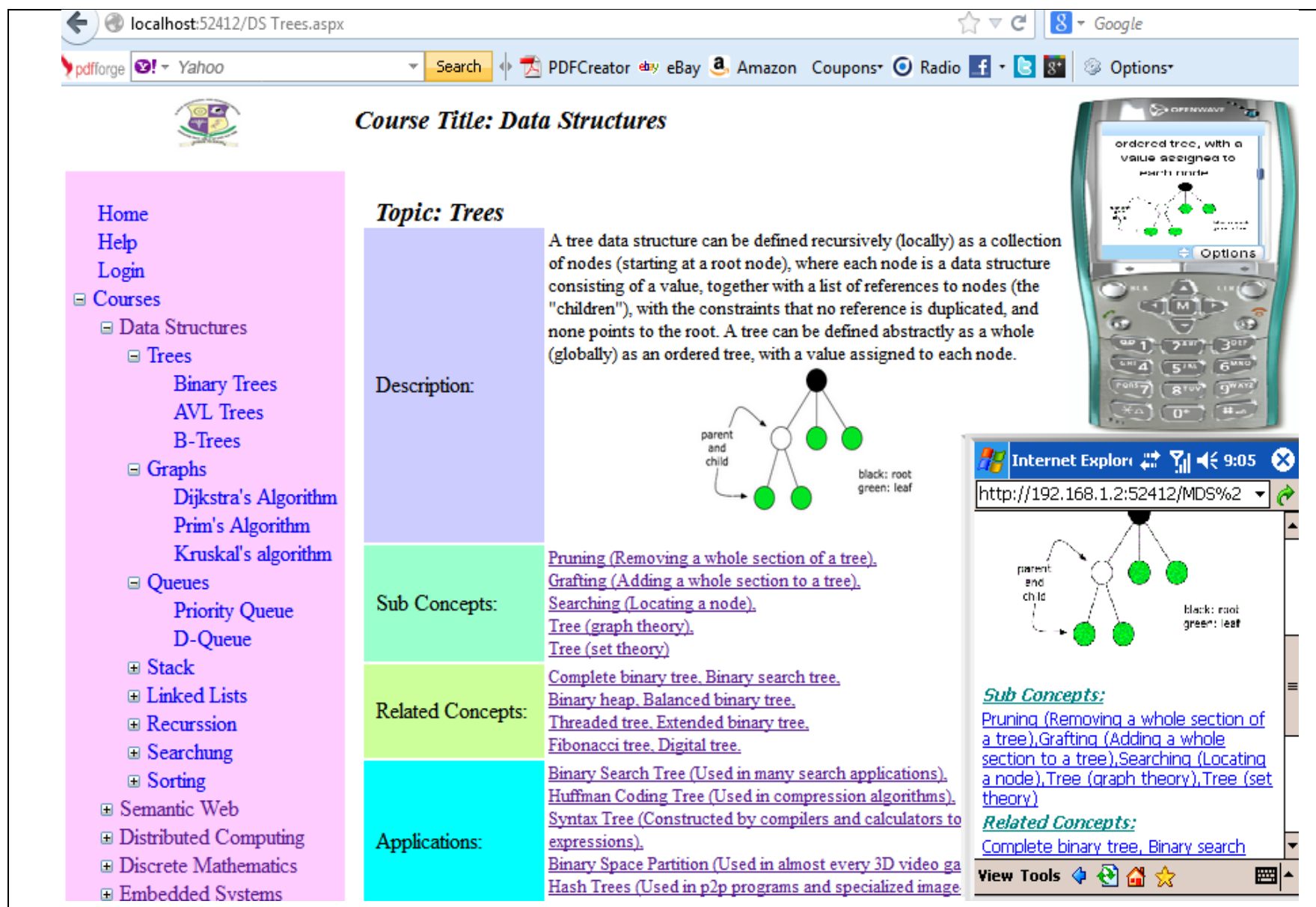

Fig. 10. Prototype Implementation

\section{PROTOTYPE IMPLEMENTATION}

Here, we illustrate the experimental results of the proposed web based prototype that is being implemented in our university. The system presents the concerned learning material according to the device context. "Fig. 10" illustrates the PC client, Feature phone (WAP based device) and Smart phone (such as iPhone) execution results of proposed context-aware content adaptation approach. For mobile environments the content-adaptation mechanism delivers the content, through breaking the webpage into several large chunks of text.

The course content presentation approach consists of base concept and other semantically related concepts that can improve the learner performance and the student has the option to freely navigate using any of the onscreen links of concerned concepts.

\section{USABILITY ANALYSIS}

In our university we conducted a questionnaire analysis before implementing the proposed prototype model. The questionnaire is on "Data Structures" subject for the students, to whom the subject is in their curriculum and the pattern of questionnaire on given concept is in the form of: what are the related concepts, examples, applications, sub concepts, etc. Unfortunately, we noticed that the average answering level is just less than $35 \%$. It indicates that students are not exposed to correlated knowledge of specific topic.

So that, the primary purpose of proposed system is to deliver topics that are concerned to the course curriculum based on learner context, but at the same time mainly focuses for enhancing the student learning outcome, through exposing students to learn presented topics that are conceptually related to learning concept. 
The prototype is implemented in our university to study its usability and the evaluation method has been used to elicit the impact and satisfaction level of learners on the proposed system. An analytical questionnaire is considered as usability metric and to solicit learners' opinion to perceive usefulness of proposed system.

The students' opinion on various questions on usefulness of proposed system is as shown in "Fig.11". The majority of

Provides additional information and support to academic course contents

Ability to access course material and makes revision of topics easier.

User friendly to search and navigate contents.

Comfortable to access in mobile environment.

Useful in Reviewing course material

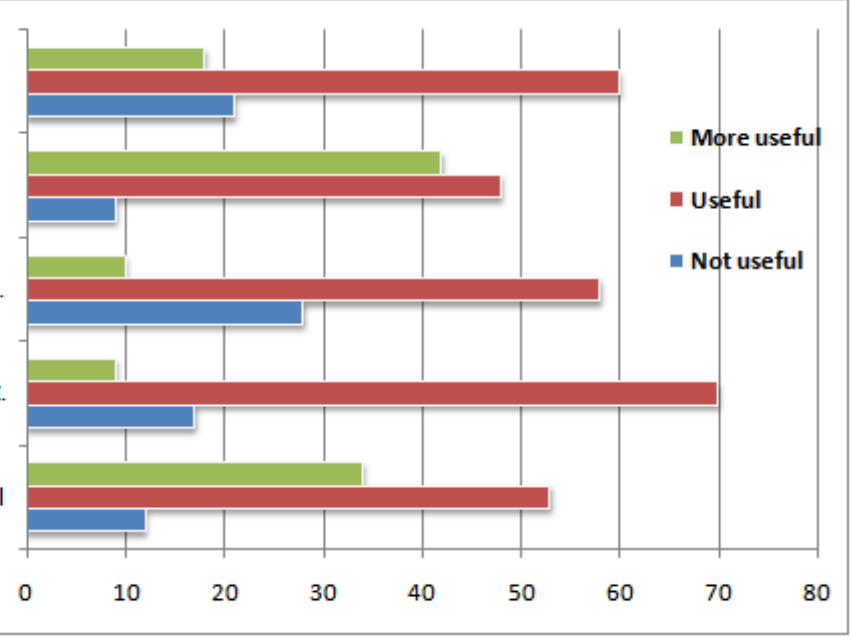

Fig. 11. Evaluation on usefulness of proposed system

\section{CONCLUSION}

This study describes the architecture of device independent course-based e-learning application using MVC design pattern and verified the context aware delivery of course contents through incorporating an ontological approach for improving understandability and knowledge level of e-learner.

In order to identify the need of device independent course learning, the prototype of proposed system implemented and verified its usability. The user-centered usability evaluation results are more likely to implement the proposed model in context aware e-learning environments.

\section{REFERENCES}

[1] Deacon, J. (2009). Model-view-controller (mvc) architecture. [Online]. Available: http://www. jdl. co. uk/briefings/MVC. pdf.

[2] Yau, J., \& Joy, M. (2007, July). "Architecture of a context-aware and adaptive learning schedule for learning Java". In Advanced Learning Technologies, 2007. ICALT 2007. Seventh IEEE International Conference on (pp. 252-256). IEEE

[3] Yau, J., \& Joy, M. (2007, April). "A Context-aware and Adaptive Learning Schedule framework for supporting learners' daily routines". In Systems, 2007. ICONS'07. Second International Conference on (pp. 3131). IEEE.

[4] Martin, E., Andueza, N., \& Carro, R. M. (2006, July). “Architecture of a System for Context-based Adaptation in M-Learning". In Advanced Learning Technologies, 2006. Sixth International Conference on (pp. 252-254). IEEE. participants endorse the idea that, proposed mobile-based course learning process can increase student's interest and engagement in e-learning, as mobile device has been an important asset for every student. However, the heuristic evaluation based on learners' opinion indicates that the system needs further improvement in delivering more useful resources and needs friendly user interface.
[5] Finke, Anita, and Janis Bicans. "E-learning System Content and Architecture volution." In Proc. of 16th International Conference on Information and Software Technologies IT, 2010. p. 11.

[6] Baylari, Ahmad, and Gh A. Montazer. "Design a personalized e-learning system based on item response theory and artificial neural network approach." Expert Systems with Applications 36, no. 4 (2009): 80138021.

[7] He, Daqing, Ming Mao, and Yefei Peng. "DiLight: a Digital Library based E-Learning Environment for Learning Digital Libraries." World Conference on E-Learning in Corporate, Government, Healthcare, and Higher Education. Vol. 2006. No. 1. 2006.

[8] Dicheva, D., \& Dichev, C. "A framework for concept-based digital course libraries". Journal of Interactive Learning Research, 2004. 15(4), 347-364.

[9] Brusilovsky, P. and Vassileva, J. "Course sequencing techniques for large-scale web-based education", Int. J. Continuing Engineering Education and Lifelong Learning. 2003. Vol. 13, Nos. 1/2, pp.75-94.

[10] Morar, G., Muntean, C., \& Tomai, N. "An Adaptive M-learning Architecture for Building and Delivering Content based on Learning Objects". Economy Informatics Journal. (2010). 10(1), 63-73.

[11] Project tomorrow (2012) "speaks up survey". Available at: http://www.tomorrow.org/speakup/MobileLearningReport2012.html

[12] Vija Vagale, Laila Niedrite. "Learner Model's Utilization in the ELearning Environments". DB \&Local Proceedings 2012: 162-174.

[13] UAProf Version 20, (2001). Available at: http://openmobilealliance.org/wp-content/uploads/2012/12/wap-248uaprof-20011020-a.pdf

[14] ASP.NET MVC 4 in Action. (2012). Manning Publications; Third Edition, Section (1.2.1), p (7) 